\title{
The Perceptions and Effects of Sleep Deprivation in a Department of Anesthesiology
}

\author{
Megan Sanders, MBChB, DipPec, DA, MMed, FCA'1, Helen Perrie, MSc ${ }^{2}$, Juan Scribante, MCur ${ }^{2}$ \\ 'Department of Anesthesiology, Chris Hani Baragwanath Academic Hospital, Johannesburg, South Africa \\ ${ }^{2}$ Department of Anaesthesiology, School of Clinical Medicine, Faculty of Health Sciences, University of the Witwatersrand, Johannesburg, South Africa
}

Received: June 10, 2018

Revised: June 21, 2018

Accepted: June 25, 2018

Correspondence

Megan Sanders, MBChB, DipPec, DA, MMed,

FCA

Department of Anaesthesiology,

Chris Hani Baragwanath Academic Hospital,

26 Chris Hani Road, Diepkloof 319-Iq,

Johannesburg 1860, South Africa

Tel +27119331843

Fax +27119331843

E-mail nutmeg.m@gmail.com

ORCID

Megan Sanders

https://orcid.org/0000-0002-1094-190X

Helen Perrie

https://orcid.org/0000-0002-9890-7887

Juan Scribante

https://orcid.org/0000-0002-2221-5024
Background and Objective Sleep deprivation has multiple pathophysiological, psychological and cognitive effects. The effects of sleep deprivation on anesthetists have been recognized both within and outside of the workplace. This study investigated the perceived effects of sleep deprivation on anesthetists. To document the longest time spent without sleep due to work schedule, to describe the perceptions of the effects of sleep deprivation and the degree of sleepiness and daytime fatigue symptoms using the Epworth Sleepiness Scale (ESS) and to describe measures taken by anesthetists to overcome sleepiness.

Methods A prospective, contextual, descriptive research design was followed for the study. A convenience sample of anesthetists completed a questionnaire regarding perceptions and effects of sleep deprivation and the ESS. Data were descriptively analyzed.

Results The mean [standard deviation (SD)] longest time spent without sleep due to work schedule was 31 (9.1) hours and all anesthetists felt that they had insufficient sleep due to work schedule, with 61 (57\%) stating this occurred 1 to 2 nights per week. Effects of sleep deprivation included effects on academic development, feeling tired at work, difficulty in concentrating at work and feeling stressed or irritable. Dozing off in theatre both during a night call and a day shift at different frequencies were reported. Other effects on family and social life were described. The mean (SD) ESS score was 11.5 (4.4).

Conclusions Anesthetists reported perceptions of inadequate sleep and the subsequent effects both at work and at home. Further research to determine the extent of sleep deprivation amongst anesthetists in South Africa is suggested.

Sleep Med Res 2018;9(1):53-57

Key Words Epworth Sleepiness Scale, Anesthetist, Sleep deprivation.

\section{INTRODUCTION}

In June 2016, South African newspapers reported on a tragic accident in which a fatigued medical intern fell asleep whilst driving home resulting in both her and another's death [1]. Similarly in the United Kingdom (UK), newspaper articles reported on the death of a fatigued anesthetist after falling asleep at the wheel [2], and other motor vehicle accidents caused by tired doctors [3]. In a forum article Erasmus [4] highlighted excessive working hours of junior doctors in South Africa [4]. A 2016/2017 national survey on the effects of fatigue amongst anesthetists training in the UK showed that $84.2 \%$ of respondents felt too tired to drive home and $57 \%$ reported a motor vehicle accident or near miss when driving home after a night shift [5].

Sleep and its importance have long been speculated upon and studied. Research has established that the average adult has 6.8 to 7.4 hours of sleep a night [6]. In today's society many shift-workers do not achieve this [6]. Less than normal sleep achieved on consecutive nights results in chronic sleep deprivation while acute sleep deprivation results from a period of complete sleep loss [6]. Sleep deprivation affects many physiological systems, as well as having 
a wide range of other effects [6]. This leads to symptoms of 'daytime sleepiness', as well as psychological and emotional consequences $[7,8]$. Sleep deprivation also has an influence on neurocognitive functioning and can result in short lapses of attention which is often termed 'microsleep' [7,9]. Dawson and Reid [10] found that after 17 hours of sleep deprivation the decline in cognitive psychomotor ability is equivalent to alcohol intoxication. Although it is difficult to test, executive functioning in the form of decision making and simulated tasks has been shown to be affected by sleep loss $[11,12]$.

Within the medical environment sleep deprivation is known to increase the risk of medical errors and have an impact on academic development of training doctors [13-15]. There are also increased risks of percutaneous injuries amongst doctors who are fatigued [16]. It has been demonstrated that sleep deprivation has an influence on the social lives and daily activities of doctors and has been linked to a negative impact on mood and personal relationships [15].

In South Africa it is known that doctors have long working hours and are sleep deprived [4]. According to the South African Society of Anesthesiologists (SASA): 'continuous on call duty of less than 12.5 hours is suggested, more than 17 hours is to be discouraged, and excess of 24 hours to be condemned' [17]. Within a Department of Anesthesiologyanesthetists are exposed to prolonged working hours and night calls. Hence the perceptions of sleep insufficiency and the longest time spent without sleep due to work schedule, as well as the effects of sleep deprivation on the work and social life of anesthetists needed to be assessed. In addition, the study aimed to describe the degree of sleepiness and daytime fatigue symptoms through the use of the Epworth Sleepiness Scale (ESS) [18] and to describe measures taken by anesthetists to overcome sleepiness.

\section{METHODS}

Approval to conduct this study was obtained from the $\mathrm{Hu}-$ man Research Ethics Committee (Medical M150106) and other relevant authorities.

A prospective, contextual, descriptive research design was followed. The study population consisted of anesthetists working in a Department of Anesthesiology, Convenience sampling was used. At the time of the study there were 131 eligible anesthetists (interns, medical officers and registrars). The sample size was determined by the number of responses and a response rate of $79(60 \%)$ completed questionnaires was regarded as an appropriate sample size [19].

Following an in-depth review of the literature a draft questionnaire was developed. The questionnaire included questions from a sleep questionnaire by Kim et al. [20] and the ESS [18]. Two senior anesthesiologists and a doctor specializing in sleep medicine reviewed the questionnaire and added five questions to the sleep questionnaire. Content and face validity was therefore ensured.

Data were collected at departmental academic meetings during October and November of 2015. Participation was voluntary and consent was implied by completion of the self-administered questionnaire. This was stipulated on the information sheet on the questionnaire. There was no identifying information on the questionnaires, which were folded and returned to a sealed box thereby ensuring anonymity. Confidentiality was ensured as only the authors had access to the raw data. One author (MS) was present at all meetings to answer any queries.

Descriptive statistics were used to analyze data. Categorical variables were described using frequencies and percentages. Likert Scale data were reported as ordinal data. The ESS scores were reported as interval data as ESS scores were presented as such in the initial study [18] and subsequently in other studies $[15,20]$. ESS total scores were normally distributed and the mean and standard deviation (SD) were used to describe the results.

\section{RESULTS}

Of the 131 distributed questionnaires, 107 (81.7\%) were returned. Not all questions were answered by all anesthetists and the number of anesthetists who answered the question is indicated where appropriate. The professional designation of anesthetists was $22(60 \%)$ interns, 15 (14\%) medical officers and 70 (66.4\%) registrars.

The mean (SD) longest time spent without sleep due to work schedule was 31 (9.1) hours. Eighty-three (88.8\%) of the 107 anesthetists answered this question. Perceptions regarding insufficient sleep due to work schedule and difficulty in awakening are shown in Table 1.

Table 2 illustrates the frequency at which anesthetists felt sleepiness affected their lives at work. The majority of anesthetists responded in the 1 to 2 days per week category for all four questions.

Fig. 1 shows the number of anesthetists who doze off in theatre both during the day and on a night call. One anesthetist

Table 1. Insufficient sleep and difficulty in awakening

\begin{tabular}{lcc}
\hline \multicolumn{1}{c}{ Response } & $\begin{array}{c}\text { Insufficient } \\
\text { sleep due } \\
\text { to work schedule } \\
\mathrm{n}(\%)\end{array}$ & $\begin{array}{c}\text { Difficulty } \\
\text { in awakening } \\
\text { in the morning } \\
\mathrm{n}(\%)\end{array}$ \\
\hline Never & 0 & $3(2.8)$ \\
1 to 2 nights per month & $13(12.1)$ & $20(18.7)$ \\
1 to 2 nights per week & $61(57)$ & $30(28)$ \\
3 to 4 nights per week & $26(24.3)$ & $30(28)$ \\
Almost always every day & $7(6.5)$ & $24(22.4)$ \\
\hline
\end{tabular}


Table 2. Sleep deprivation at work

\begin{tabular}{lcccc}
\hline \multicolumn{1}{c}{ Response } & Tired at work & Difficulty in concentrating & Sleepiness on academic development & Stressed or irritable \\
$\mathrm{n}(\%)$ & $\mathrm{n}(\%)$ & $2(\%)$ & $3(2.8)$ \\
\hline Never & $1(0.9)$ & $4(3.7)$ & $17(15.9)$ & $27(25.2)$ \\
1 to 2 days per month & $12(11.2)$ & $39(36.4)$ & $46(43)$ & $47(43.9)$ \\
1 to 2 days per week & $48(44.9)$ & $42(39.3)$ & $26(24.3)$ & $24(22.4)$ \\
3 to 4 days per week & $28(26.2)$ & $15(14)$ & $16(15)$ & $6(5.6)$ \\
Almost always every day & $18(16.9)$ & $7(6.5)$ & \\
\hline
\end{tabular}

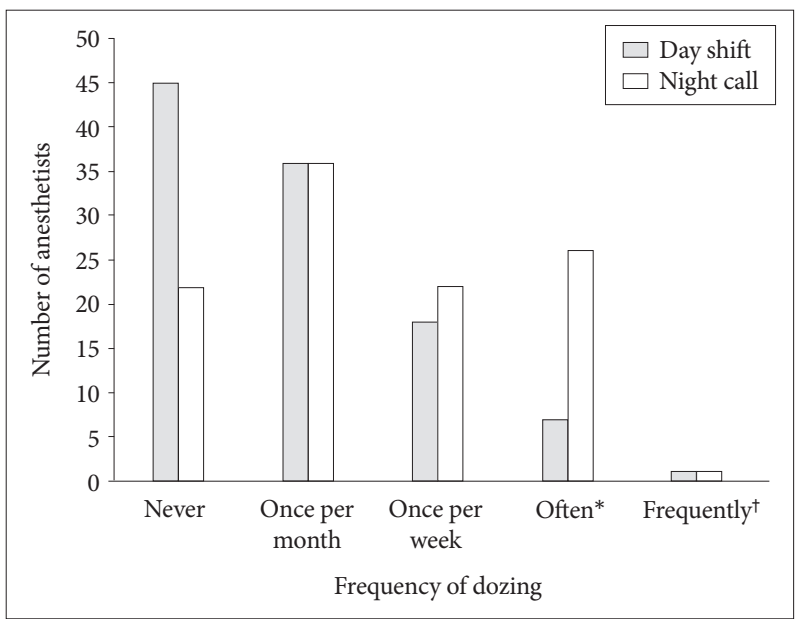

Fig. 1. Frequency of dozing off in theatre. *more than once per week/ almost every day. ${ }^{\dagger}$ almost every day/more than once per night call.

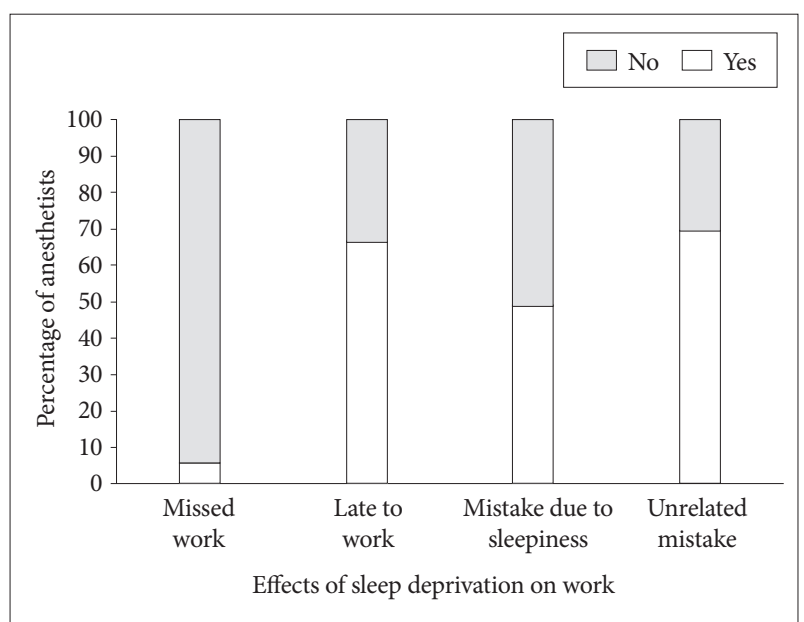

Fig. 2. Effects of sleep deprivation on work.

Table 3. Use of caffeinated beverages

\begin{tabular}{|c|c|c|c|c|c|c|}
\hline Units & $\begin{array}{c}\text { Filter coffee } \\
\mathrm{n}(\%)\end{array}$ & $\begin{array}{c}\text { Instant coffee } \\
\mathrm{n}(\%)\end{array}$ & $\begin{array}{c}\text { Ceylon tea } \\
\mathrm{n}(\%)\end{array}$ & $\begin{array}{c}\text { Herbal tea } \\
\text { n (\%) }\end{array}$ & $\begin{array}{c}\text { Cold drink } \\
\mathrm{n}(\%)\end{array}$ & $\begin{array}{c}\text { Energy drink } \\
\mathrm{n}(\%)\end{array}$ \\
\hline 0 units & $80(74.8)$ & $55(51.4)$ & $88(82.2)$ & $96(89.7)$ & $68(63.6)$ & $91(85)$ \\
\hline 1 to 2 units & $19(17.8)$ & $42(39.2)$ & $14(13.1)$ & $10(9.3)$ & $38(35.5)$ & $16(15)$ \\
\hline 3 to 4 units & $4(3.7)$ & $9(8.4)$ & $5(4.7)$ & $1(0.9)$ & $1(0.9)$ & 0 \\
\hline$>4$ units & $4(3.7)$ & $1(0.9)$ & 0 & 0 & 0 & 0 \\
\hline
\end{tabular}

reported dozing off in theatre every day and more than once per night call.

Other effects of sleep deprivation on work are shown in Fig. 2.

The majority, 99 (92.5\%) anesthetists, have missed social and family activities, $44(41.1 \%)$ a percutaneous injury on duty and 101 (94.4\%) felt at risk of having a motor vehicle accident because of sleepiness.

The mean (SD) ESS score was 11.5 (4.4) indicating mild sleepiness. Forty-six (43.4\%) anesthetists had a normal score $(0$ $-10), 32$ (30.2\%) had mild sleepiness (11-14), 19 (17.9\%) had moderate sleepiness (15-17) and 9 (8.5\%) had severe sleepiness (18 or higher). One anesthetist did not complete the ESS.

Thirty-two (29.9\%) anesthetists reported that they drink caffeinated beverages 1 to 2 times per day. Table 3 illustrates the use of caffeinated beverages during a night call. One unit is $250 \mathrm{~mL}$ or one cup.
Other strategies used by anesthetists to resist sleepiness are represented in Fig. 3. Some anesthetists used more than one strategy.

\section{DISCUSSION}

Sleep deprivation and the effects thereof are well described in the literature, however no South African study on the effects of sleep deprivation on anesthetists could be identified. Extensive research on sleep deprivation amongst health care workers has been conducted and a wide variety of methods have been used to describe the phenomena. Where standardized scales or questionnaires where used the results were not always reported in a standardized manner. This makes direct comparison with other studies difficult. 


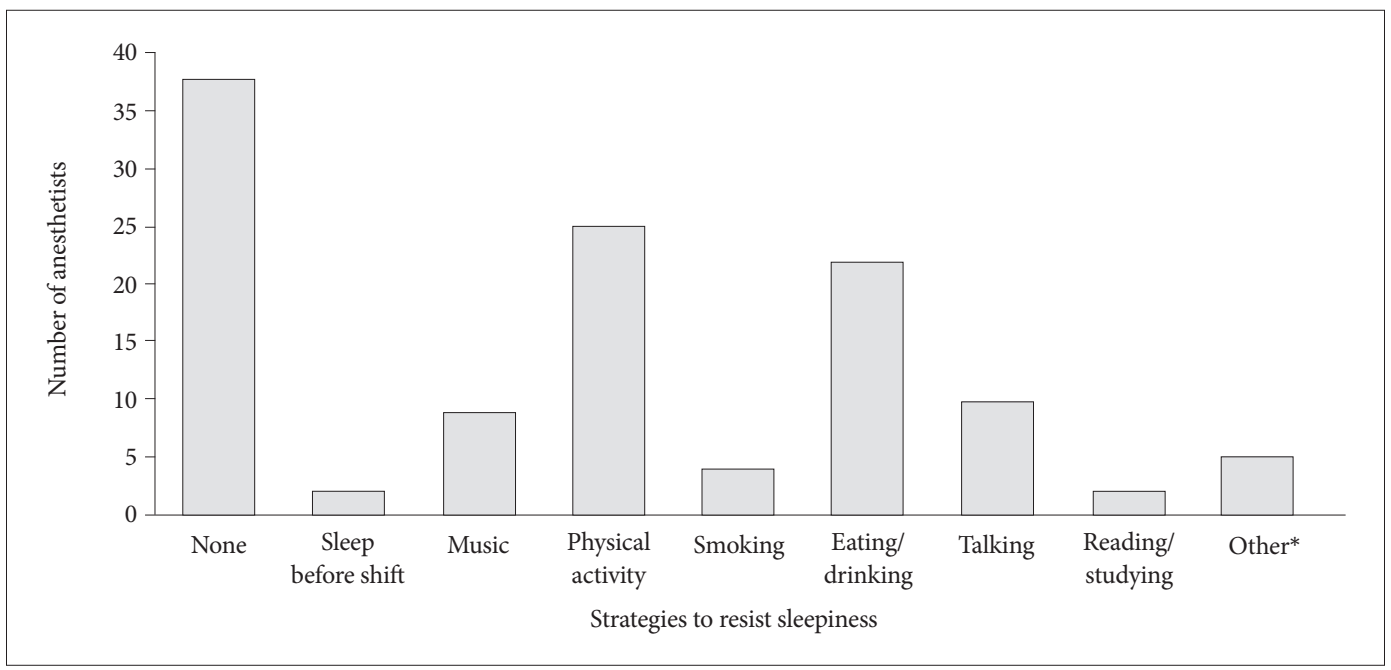

Fig. 3. Strategies to resist of sleepiness. *games, social media, cleaning etc.

SASA guidelines [17] suggest that a work period in excess of 24 hours should be condemned. In this study working hours vary from approximately 8 to 28 hours between the different hospitals affiliated to the department. Kim et al. [20] reported a mean work duration of 14.9 (2.7) hours per day and the longest length of time participants had gone without sleep due to work schedule was a mean of 38.5 (15.7) hours. Gander et al. [21] reported mean continuous work hours of 18.6 (6.8) for training anesthetists and 20.5 (4.96) for specialist anesthetists.

The mean longest length of time anesthetists had gone without sleep due to work schedule was 31 (9.1) hours in this study. This may be accounted for by anesthetists being awake for some time before and after their work period. Additional hours spent awake may involve meetings or academic tutorials and include travel time. Family or social activities may further prolong the time awake. Frequent calls with resulting sleep fragmentation as a reason for long hours of wakefulness has also been suggested in the literature [20].

This study showed a mean ESS score of 11.5 which falls into the mild sleepiness category according to the Division of Sleep Medicine at Harvard Medical School [22]. This much higher than the mean score of normal adults of 4.6 [23], however lower than the mean score of 14.6 reported for residents-physician by Papp et al. [15] In this study all anesthetists reported insufficient sleep due to work schedule, and $57 \%$ of anesthetists perceived insufficient sleep due to work schedule 1 to 2 nights per week which coincides with the night calls per week. McClelland et al. [5] reported that $81.7 \%$ of respondents had less than 30 minutes uninterrupted sleep during a night shift and 95.1\% had disrupted sleep while off duty to varying degrees.

Screening for Obstructive Sleep apnea was not used for this study, as it was not part of the scope for the study. However it is noted that this may have influenced results such as the ESS score, and could be included in future studies.

Feeling tired at work (44.9\%), having difficulty in concen- trating at work (39.3\%), effect on academic development (43\%) and feeling stressed and irritable (43.9\%) also appears to correspond to the weekly calls 1 to 2 nights per week. However, this sleep deprivation perceived by anesthetists may not only be from shift work but also from long standing chronic sleep loss. McClelland et al. [5] reported that fatigue affected the ability of over $50 \%$ of the respondents to do their jobs and over $80 \%$ of respondents felt fatigue affected management of exams and audits.

Sleep deprivation not only affects the junior doctor personally but also impacts on patient safety and service delivery. In this study, $57.9 \%$ of the anesthetists reported dozing off in theatre during the day and $79.4 \%$ during a night call with varying degrees of regularity. In a study by Howard et al. [9] one third of sleep deprived participants fell asleep during simulations. Missing work was reported by $5.6 \%$ of anesthetists and $66.4 \%$ had been late to work due to sleep problems in this study. Kim et al. [20] reported a higher $37.9 \%$ of the participants admitting to missing work and a similar $60.3 \%$ admitting to lateness because of sleep problems.

Almost half (48.6\%) of the anesthetists in this study admitted to making a sleepiness related mistake and 69.2\% admitted to making a mistake at work unrelated to sleepiness. Kim et al. [20] reported $60.3 \%$ of the participants making a sleepiness related mistake and $67.2 \%$ making a non-sleepiness related mistake. Both studies illustrated making mistakes unrelated to sleepiness is more common than mistakes related to sleepiness. It could be argued that anesthetists felt mistakes are multifactorial and can occur regardless of fatigue status. This is supported by the findings of Morris and Morris [24], who documented factors such as haste, distraction, other stress and equipment issues could be linked to errors. The authors further indicated that fatigue may play a more significant role for specific errors such as pharmacological errors. Percutaneous injury secondary to sleepiness was perceived by $41.1 \%$ of anesthetists from 
this study. Ayas et al. [16] reported that $31 \%$ of interns linked fatigue to percutaneous injuries. The authors also suggested other possible causation factors such as lapse in concentration, inadequate lighting and patient movement, supporting the theory that multiple factors may lead to percutaneous injuries [16].

McClelland et al's. [5] 2017 national survey in the UK on the effects of fatigue on trainees in anaesthesia [5] reported that $84.2 \%$ felt too tired to drive home after a night shift. The authors also reported $57 \%$ had had an accident or near miss when driving home after a night shift. South African [1] and international news [2,3] have reported on fatal car accidents involving fatigued doctors. A perception of risk of accident when driving while being sleepy was found in $94.4 \%$ anesthetists in this study.

Although anesthetists in this study indicated that they perceived their sleep to be insufficient to varying degrees, traditional strategies to reduce sleepiness where not always used. Caffeinated beverages were consumed by $29 \%$ of anesthetists 1 to 2 times per day. Kim et al. [20] participants seldom drank caffeinated beverages, however, $87.9 \%$ of McClelland et al's. [5] participants used caffeine to counteract the effects of fatigue. Only $1.9 \%$ of anesthetists in this study reported sleeping before a shift and $21 \%$ reported eating and drinking to reduce sleepiness. It was noted that no anesthetist reported the use of medication or other substances, however this could be because it is a socially unacceptable answer.

In conclusion, this study focusses on the perceptions of sleep deprivation of junior anesthetists in one department and gives insight to the understanding of sleep deprivation amongst junior anesthetists. Junior doctors are the backbone of health service delivery in South Africa. Although the working hours and effects of fatigue were highlighted by Erasmus [4] in 2012, further research is needed to establish the level of sleep deprivation and its effects on the lives of both senior junior doctors in all specialties.

\section{Conflicts of Interest}

The authors have no financial conflicts of interest.

\section{Authors' Contribution}

Conceptualization: Sanders M. Data curation: Sanders M, Perrie H, Scribante J. Investigation: Sanders M. Methodology: Sanders M, Perrie H, Scribante J. Supervision: Perrie H, Scribante J. Writing-original draft: Sanders M. Writing-review \& editing: Perrie H, Scribante J.

\section{REFERENCES}

1. Phaliso S. Tired doctor's car crash victim dies [cited 2018 Jan 20]. Available from: https://www.iol.co.za/news/crime-courts/tired-doctors-car-crash-victim-dies-2039771.]

2. Cambridge E. Crash tragedy exhausted doctor died in car accident after falling asleep at the wheel while singing to his wife on a handsfree phone to try and stay awake [cited 2018 Jan 20]. Available from: https:// www.thesun.co.uk/news/1442420/exhausted-doctor-died-in-car-acci- dent-after-falling-asleep-at-the-wheel-while-singing-to-his-wife-on-ahands-free-phone-to-try-and-stay-awake/.

3. Johnson S. 'I fell asleep at the wheel': the dangers of doctors driving home [cited 2018 Jan 20]. Available from: https://www.theguardian. com/healthcare-network/2016/jul/26/two-in-five-doctors-fallenasleep-wheel-night-shift.

4. Erasmus N. Slaves of the state-medical internship and community service in south africa. S Afr Med J 2012;102:655-8.

5. McClelland L, Holland J, Lomas JP, Redfern N, Plunkett E. A national survey of the effects of fatigue on trainees in anaesthesia in the UK. Anaesthesia 2017;72:1069-77.

6. Banks S, Dinges DF. Behavioral and physiological consequences of sleep restriction. J Clin Sleep Med 2007;3:519-28.

7. Durmer JS, Dinges DF. Neurocognitive consequences of sleep deprivation. Semin Neurol 2005;25:117-29.

8. Tewari A, Soliz J, Billota F, Garg S, Singh H. Does our sleep debt affect patients' safety? Indian J Anaesth 2011;55:12-7.

9. Howard SK, Gaba DM, Smith BE, Weinger MB, Herndon C, Keshavacharya $S$, et al. Simulation study of rested versus sleep-deprived anesthesiologists. Anesthesiology 2003;98:1345-55.

10. Dawson D, Reid K. Fatigue, alcohol and performance impairment. Nature 1997;388:235.

11. Harrison Y, Horne JA. The impact of sleep deprivation on decision making: a review. J Exp Psychol Appl 2000;6:236-49.

12. Lopez N, Previc F, Fischer J, Heitz R, Engle R. Effects of sleep deprivation on cognitive performance by United States Air Force pilots. J Appl Res Mem Cogn 2012;1:27-33.

13. Barger LK, Ayas NT, Cade BE, Cronin JW, Rosner B, Speizer FE, et al. Impact of extended-duration shifts on medical errors, adverse events, and attentional failures. PLoS Med 2006;3:e487.

14. Rothschild JM, Keohane CA, Rogers S, Gardner R, Lipsitz SR, Salzberg CA, et al. Risks of complications by attending physicians after performing nighttime procedures. JAMA 2009;302:1565-72.

15. Papp KK, Stoller EP, Sage P, Aikens JE, Owens J, Avidan A, et al. The effects of sleep loss and fatigue on resident-physicians: a multi-institutional, mixed-method study. Acad Med 2004;79:394-406.

16. Ayas NT, Barger LK, Cade BE, Hashimoto DM, Rosner B, Cronin JW, et al. Extended work duration and the risk of self-reported percutaneous injuries in interns. JAMA 2006;296:1055-62.

17. SASA Statement: Working hours [Internet]. South African Society of Anaesthesiologists [cited 2014 Oct 16]. Available from: www.sasaweb. com/content/images/SASA\%20Statement\%20Working\%20hours.pdf.

18. Johns MW. A new method for measuring daytime sleepiness: the Epworth sleepiness scale. Sleep 1991;14:540-5.

19. Draugalis JR, Coons SJ, Plaza CM. Best practices for survey research reports: a synopsis for authors and reviewers. Am J Pharm Educ 2008; $72: 11$.

20. Kim HJ, Kim JH, Park KD, Choi KG, Lee HW. A survey of sleep deprivation patterns and their effects on cognitive functions of residents and interns in Korea. Sleep Med 2011;12:390-6.

21. Gander PH, Merry A, Millar MM, Weller J. Hours of work and fatigue-related error: a survey of new zealand anaesthetists. Anaesth Intensive Care 2000;28:178-83.

22. Division of Sleep Medicine HMS. Epworth Sleepiness Scale 2013 [cited 2015 Aug 1]. Available from: http://healthysleep.med.harvard.edu/ narcolepsy/diagnosing-narcolepsy/epworth-sleepiness-scale.

23. The Epworth Sleepiness Scale [cited 2015 Oct 1]. Available from: http:// epworthsleepinessscale.com/about-the-ess/.

24. Morris GP, Morris RW. Anaesthesia and fatigue: an analysis of the first 10 years of the australian incident monitoring study 1987-1997. Anaesth Intensive Care 2000;28:300-4. 